\title{
Safety and disease response to MEDI-551, an anti-CD19 antibody, in chronic lymphocytic leukemia patients previously treated with rituximab
}

\author{
Andres Forero ${ }^{1 *}$, Mehdi Hamadani ${ }^{2}$, Thomas Kipps ${ }^{3}$, Michelle Fanale $^{4}$, Antonio Cuneo ${ }^{5}$, Jaime Perez de Oteyza ${ }^{6}$, \\ Douglas Gladstone ${ }^{7}$, Marc Andre ${ }^{8}$, Naresh Bellam ${ }^{1}$, Trishna Goswami ${ }^{9}$, Ramy Ibrahim ${ }^{9}$, Amy Schneider ${ }^{10}$, \\ Meina Liang ${ }^{10}$, Steven Eck ${ }^{9}$, Nairouz Elgeioushi ${ }^{9}$, Ronald Herbst ${ }^{9}$, Bruce D Cheson ${ }^{11}$
}

From Society for Immunotherapy of Cancer 28th Annual Meeting

National Harbor, MD, USA. 8-10 November 2013

\section{Background}

The expression of CD19 on chronic lymphocytic leukemia (CLL) cells offers a novel therapy for relapsed CLL patients (pts) previously treated with rituximab. MEDI551 is an affinity-optimized anti-CD19 Ab with enhanced Ab-dependent cellular cytotoxicity (ADCC) effector function.

\section{Methods}

Response and toxicity of single-agent MEDI-551 in multiply relapsed CLL pts with prior rituximab therapy was assessed in a phase $1 / 2$ (ph 1/2), open-label, dose-escalation and expansion study. Combination therapy was assessed in an ongoing phase 2 (ph 2) study comparing MEDI-551 or rituximab+bendamustine in relapsed/refractory CLL pts. For the ph 1/2 study, B cell depletion was assessed with flow cytometry and BAFF biomarker analysis; response was assessed using the 2008 IWG criteria.

\section{Results}

In the ph $1 / 2$ study, 26 CLL pts received $\geq 1$ dose of MEDI-551. In the ph 2 study, 44 pts received study drug as of 20Mar2013. Loss of CD19 detection due to depletion and/or occupancy with MEDI-551 was rapid and apparent after cycle 1 . B cell depletion occurred 1 day after dose 1 and was associated with increased serum BAFF concentrations. In the ph 1/2 study, of 21 MEDI-551-treated CLL pts evaluable for response, 5 achieved partial remission and 13 had stable disease. Commonly reported adverse events (AEs) in MEDI-551 pts were infusion-related reactions (IRRs; 62\%), nausea (23\%), pyrexia (23\%), and neutropenia (23\%) in the 26 ph $1 / 2$ pts; in the 29 ph 2 pts, they were nausea $(62 \%)$, IRRs $(31 \%)$, pyrexia $(28 \%)$, chills (28\%), and fatigue (28\%). 11 pts had $\geq$ grade 3 AEs in the ph $1 / 2$ study and 16 in the ph 2 . Common treatmentrelated AEs: IRRs (58\%) and nausea (12\%) in the ph $1 / 2$; nausea (52\%), IRRs (28\%), chills (24\%), and fatigue (24\%) in the ph 2. Three treatment-unrelated AEs of general health deterioration ( $\mathrm{ph} 1 / 2$ ), subarachnoid hemorrhage (ph 1/2), and sepsis (ph 2), resulted in death.

\section{Conclusions}

MEDI-551 as a single agent demonstrated B-cell depletion, increased serum BAFF levels, clinical activity, and an acceptable risk-benefit profile in relapsed/refractory CLL pts. Preliminary results of the ongoing ph 2 study of MEDI-551+bendamustine demonstrated an acceptable safety profile.

\footnotetext{
Authors' details

${ }^{1}$ University of Alabama at Birmingham, Birmingham, AL, USA. ${ }^{2}$ West Virginia University, Morgantown, WV, USA. ${ }^{3}$ Moores UCSD Cancer Center, San Diego CA, USA. ${ }^{4}$ University of Texas, Houston, TX, USA. ${ }^{5}$ Azienda Ospedaliera Universitaria Arcispedale Sant'Anna, Ferrara, Italy. ${ }^{6}$ Centro Integral Oncologico Clara Campal, Madrid, Spain. ${ }^{7} J o h n s$ Hopkins University, Baltimore, MD, USA ${ }^{8} \mathrm{CHU}$ Mont-Godinne, Yvoir, Belgium. ${ }^{9}$ Medlmmune, Gaithersburg, MD, USA. ${ }^{10}$ Medlmmune, Gaithersburg, CA, USA. ${ }^{11}$ Georgetown University Hospital, Washington DC, MD, USA.
} 
doi:10.1186/2051-1426-1-S1-P43

Cite this article as: Forero et al.: Safety and disease response to MEDI551, an anti-CD19 antibody, in chronic lymphocytic leukemia patients previously treated with rituximab. Journal for ImmunoTherapy of Cancer 2013 1(Suppl 1):P43.

Submit your next manuscript to BioMed Central and take full advantage of:

- Convenient online submission

- Thorough peer review

- No space constraints or color figure charges

- Immediate publication on acceptance

- Inclusion in PubMed, CAS, Scopus and Google Scholar

- Research which is freely available for redistribution

Submit your manuscript at www.biomedcentral.com/submit
() Biomed Central 